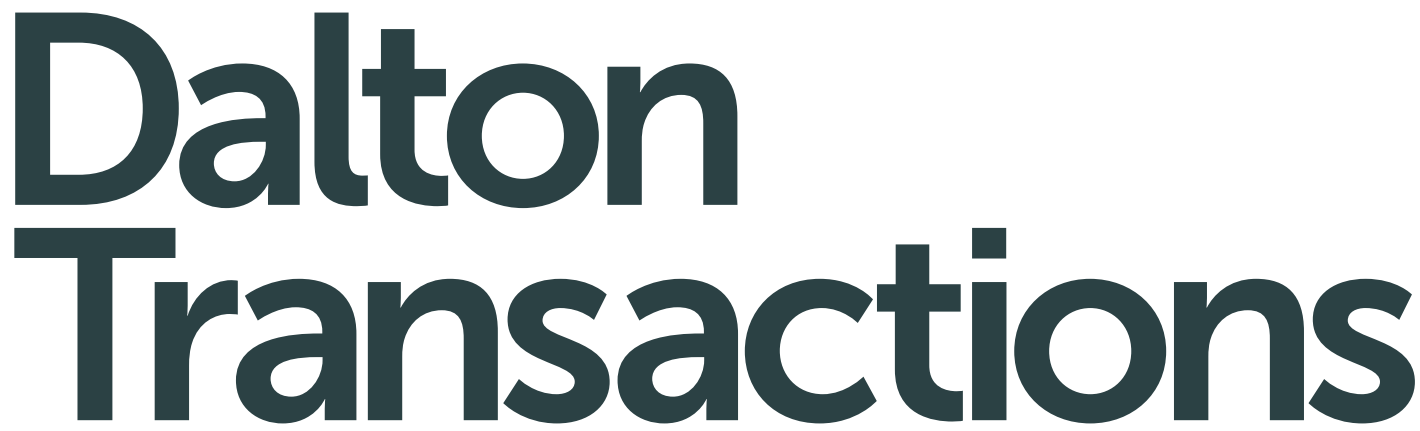

An international journal of inorganic chemistry

www.rsc.org/dalton
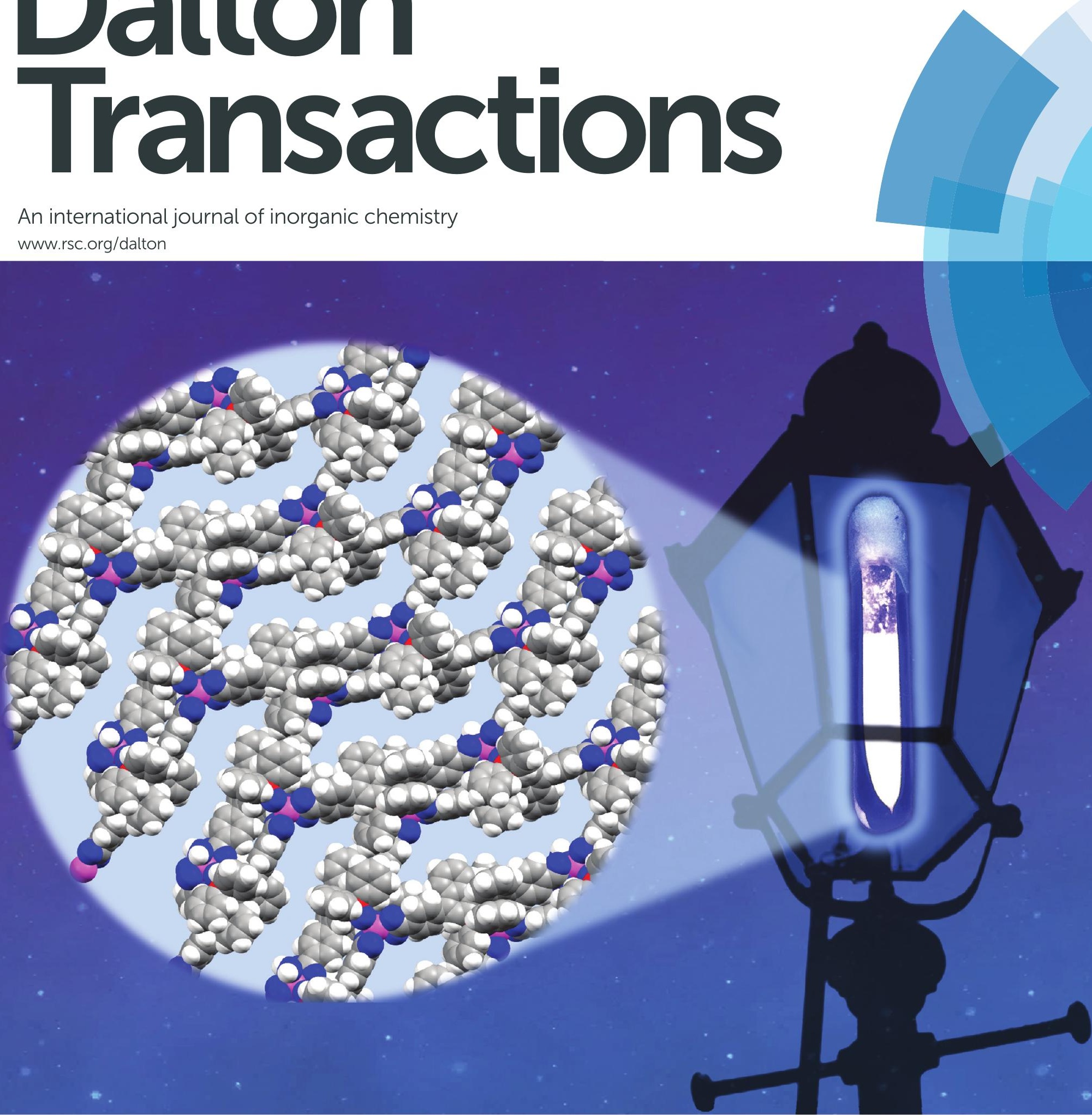

ISSN $1477-9226$

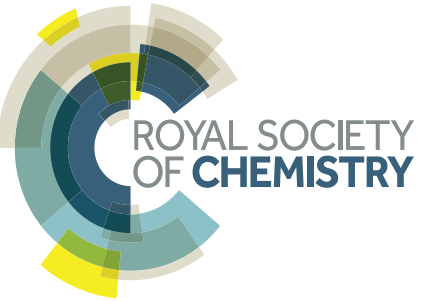

\title{
PAPER
}

Claudia Wickleder, Evamarie Hey-Hawkins et al.

Synthesis, structure and luminescence properties of a cadmium(II)based coordination polymer with (S)-4,4'-bis(4-carboxyphenyl)-2,2'-

bis(diphenylphosphinoyl)-1,1'-binaphthyl as chiral linker 


\title{
Dalton Transactions
}

Cite this: Dalton Trans., 2014, 43 8188

Received 17th December 2013, Accepted 1st February 2014

DOI: $10.1039 / c 3 d t 53543 f$

www.rsc.org/dalton

\section{Synthesis, structure and luminescence properties of a cadmium(II)-based coordination polymer with (S)-4,4'-bis(4-carboxyphenyl)- 2,2'-bis(diphenylphosphinoyl)-1,1'-binaphthyl as chiral linker $\dagger$}

\author{
Witri Wahyu Lestari, ${ }^{a}$ Huayna Cerqueira Streit, ${ }^{b}$ Peter Lönnecke, ${ }^{a}$ \\ Claudia Wickleder ${ }^{\star b}$ and Evamarie Hey-Hawkins ${ }^{\star a}$
}

\begin{abstract}
Solvothermal reaction of cadmium(II) nitrate with (S)-4,4'-bis(4-carboxyphenyl)-2,2'-bis(diphenylphosphinoyl)-1,1'-binaphthyl $\left(\mathbf{H}_{\mathbf{2}} \mathrm{L}\right)$ in dimethylformamide $(\mathrm{dmf})$ gave the two-dimensional chiral coordination polymer $\left[\left\{\mathrm{Cd}_{2}\left(\mathrm{~L}_{2}\left(\mathrm{H}_{2} \mathrm{O}\right)\right\} \cdot 18 \mathrm{dmf}\right]_{n}(\mathbf{1})\right.$, which is thermally stable up to $400{ }^{\circ} \mathrm{C}$ according to DTA/TG analysis. According to single-crystal X-ray analysis, $\mathbf{1}$ forms layers in the [1]01] direction, which are relatively well separated from each other. Compound 1 exhibits ligand-based bluish luminescence, assigned to the $\mathrm{S}_{1} \rightarrow \mathrm{S}_{0}$ transition of the aromatic units in L. Emission spectra consist of nearly Gaussian shaped bands with maxima at 25574 and $24767 \mathrm{~cm}^{-1}$ for $\mathrm{H}_{2} \mathrm{~L}$ and $\mathbf{1}$, respectively. Quantum efficiency reaches a remarkably high value of $42 \%$ for the $\mathrm{Cd}$-based coordination polymer and $33 \%$ for the respective ligand. Emission intensity of 1 increases from $10 \mathrm{~K}$ to room temperature and decreases exponentially for temperatures up to $650 \mathrm{~K}$.
\end{abstract}

\section{Introduction}

Extended structures with permanent porosity, so-called metalorganic frameworks (MOFs) ${ }^{1}$ have received much attention during the past decade. These coordination polymers can be one-dimensional structures such as chains, ladders, or tapes, ${ }^{2}$ or two- and three-dimensional porous networks containing metal cations linked by suitable ligands to give infinite arrays,$^{2-4}$ which can exhibit diverse properties for a broad range of applications. Specific properties, such as gas sorption, separation and catalytic function, are influenced by the structure. ${ }^{5}$ To modify these properties, the topology, rigidity and functionality of the ligands, as well as the metal cations, can be varied. Physical properties such as magnetism and

\footnotetext{
${ }^{a}$ Institut für Anorganische Chemie, Fakultät für Chemie und Mineralogie, Universität Leipzig, Johannisallee 29, D-04103 Leipzig, Germany.

E-mail: hey@rz.uni-leipzig.de; Fax: +49 3419739319

${ }^{b}$ Anorganische Chemie II, Naturwissenschaftlich-Technische Fakultät, Department Chemie-Biologie, Universität Siegen, Adolf-Reichwein-Straße, D-57068 Siegen, Germany.E-mail:wickleder@chemie.uni-siegen.de; Fax: +49 2714702555 $\dagger$ Electronic supplementary information (ESI) available: Powder X-ray diffraction and thermal analysis of 1. CCDC 958436. For ESI and crystallographic data in CIF or other electronic format see DOI: 10.1039/c3dt53543f
}

luminescence result from combining intrinsic properties of the metal cations and the organic ligands. ${ }^{2 b, 5}$

Different approaches have been applied to explore the luminescence properties of coordination polymers and MOFs. ${ }^{6}$ The ligand-based approach utilises the emission of light by extended conjugated $\pi$ systems of the organic linker., Another possibility is the use of emitting ions, e.g., lanthanides, as connecting points in the framework ${ }^{6,8}$ or as guests within the pores of the framework. ${ }^{6,9}$ Luminescence of coordination polymers and MOFs containing transition metals ions is typically centred on the linker rather than on the metal. Thus, transition metal ions without unpaired electrons, such as $\mathrm{Zn}^{\mathrm{II}}$ and $\mathrm{Cd}^{\mathrm{II}}$, can yield linker-based highly emissive materials. ${ }^{6,10,11}$ Furthermore, molecular interactions can bring luminophores closer together in the solid state and thus enable electronic interactions between them (e.g., ligand-toligand charge transfer), which can cause spectral shifts, emission broadening, loss of vibronic structure, and increased emission lifetimes and quantum yields. Controlling these ligand-ligand interactions is important for applications that involve charge transport and to obtain tuneable emission colours. ${ }^{6}$

Employment of aromatic systems such as functionalised binaphthyl-derived ligands ${ }^{12-15}$ as rigid linkers yields homochiral coordination polymers that have been studied in 
enantioselective processes ${ }^{13 a}$ and asymmetric catalysis, ${ }^{14 a-d}$ for chiral sensing ${ }^{13 d, 15}$ and as luminescent materials. ${ }^{13 b, c}$ Furthermore, some one- and two-dimensional coordination polymers containing phosphorus or the oxygen atom of phosphine oxides as donors and silver(I), ${ }^{16} \operatorname{gold}(\mathrm{I})^{17}$ and indium(III) ${ }^{18}$ exhibit strong luminescence properties. Herein, we present the synthesis, structure and optical properties of a chiral coordination polymer, namely, $\left[\left\{\mathrm{Cd}_{2}(\mathbf{L})_{2}\left(\mathrm{H}_{2} \mathrm{O}\right)\right\} \cdot 18 \mathrm{dmf}\right]_{n}(\mathbf{1})$, which is based on $\mathrm{Cd}^{\mathrm{II}}$ and $(S)-4,4^{\prime}$-bis(4-carboxyphenyl)-2,2'-bis(diphenylphosphinoyl)-1,1'-binaphthyl as linker. Some Cd-based MOFs with $1,3-$ or 1,4-benzenedicarboxylate (BDC) and its derivatives ${ }^{19}{ }^{19} 2,2^{\prime}-, \quad 3,3^{\prime}-, \quad 3,4^{\prime}$ or $4,4^{\prime}$-biphenyl dicarboxylate $(\mathrm{BPDC})^{19 d, 20}$ or modified 2,2'-, 4,4'-, 6,6'- or 3,3'-di- and tetracarboxylate binaphthyl linkers and their derivatives ${ }^{11,15}$ exhibit versatile geometrical arrangements around the $\mathrm{Cd}^{\mathrm{II}}$ cation, showing coordination numbers of 4 to $8 .^{11,15,19,20}$ Even a coordination number of 9 was observed with oxalato ligands as linkers giving rise to a diamondoid network. ${ }^{21}$

\section{Results and discussion}

The reaction of $\mathbf{H}_{2} \mathbf{L}^{22}$ with cadmium(II) nitrate under solvothermal conditions in $\mathrm{dmf}$ progressively heated to 65,75 and $85{ }^{\circ} \mathrm{C}$ (each for $24 \mathrm{~h}$ ) gave $2 \mathrm{D}$ coordination polymer 1 , which is insoluble in water and organic solvents (Scheme 1). Compound 1 crystallises in the monoclinic space group C2 with four molecules in the unit cell.

1 forms layers in [101] (Fig. 2) in which two differently coordinated cadmium atoms are linked via dianionic $\mathbf{L}$ ligands. One cadmium atom (Cd1) is hexacoordinate, and the other (Cd2) heptacoordinate. Both cadmium atoms are coordinated by two bidentate $\mathrm{COO}$ groups $\left(\mathrm{O}-\mathrm{Cd}-\mathrm{O}\right.$ 53.2(2)-57.1(2) ${ }^{\circ}$, Cd1O 2.283(5)-2.336(5) $\AA$ and Cd2-O from 2.291(5) to 2.437(7) $\AA$, Table 1). The $\mathrm{O}-\mathrm{Cd}-\mathrm{O}$ bond angles and $\mathrm{Cd}-\mathrm{O}$ bond lengths are in a good agreement with those reported in the literature for similar compounds. ${ }^{19 c-f, 20 a, c}$ Additionally, the two oxygen atoms of the bis(phosphine oxide) fragment coordinate to both cadmium atoms in a chelating fashion, forming ninemembered rings (Cd1-O1-P1-C1-C2-C12-C11-P2-O2 and Cd2-O7-P3-C59-C60-C70-C69-P4-O8, Fig. 1b) with O-Cd-O

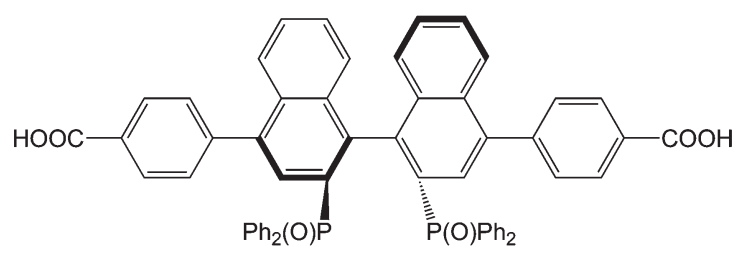

$\mathrm{H}_{2} \mathrm{~L}$

$2 \mathrm{H}_{2} \mathrm{~L}+2 \mathrm{Cd}\left(\mathrm{NO}_{3}\right)_{2} \cdot 4 \mathrm{H}_{2} \mathrm{O} \underset{\substack{65,75,85^{\circ} \mathrm{C} \\(\text { each for } 24 \mathrm{~h})}}{\stackrel{\mathrm{dmf}}{\longrightarrow}}\left[\left\{\mathrm{Cd}_{2}(\mathrm{~L})_{2}\left(\mathrm{H}_{2} \mathrm{O}\right)\right\} \cdot 18 \mathrm{dmf}\right]_{n}$

Scheme 1 Synthesis of 1. bond angles of 79.8(2) and 81.5(2) and $\mathrm{Cd}-\mathrm{O}$ bond lengths of 2.209(5) (Cd1-O1) to 2.301(6) (Cd2-O7) A, respectively. The dihedral angles between the binaphthyl rings are slightly smaller (76.7(3) and $\left.79.6(4)^{\circ}\right)$ than the dihedral angle of the free ligand $\left(82.05(4)^{\circ}\right) .{ }^{22}$ Furthermore, one water molecule is coordinated to $\mathrm{Cd} 2$ (Cd2-O13 2.409(8) ̊) (Fig. 1a). The topology of the resulting two-dimensional network shows a 3-c net with point (Schläfli) symbol $\left\{4.8^{2}\right\}$ according to TOPOS ${ }^{23}$ (Fig. 3) and the RCSR database. ${ }^{24}$

The dmf molecules occupy the space between the layers. The water molecule coordinated to $\mathrm{Cd} 2$ forms hydrogen bonds

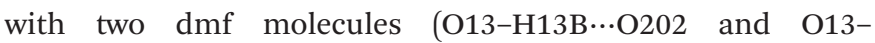
$\mathrm{H} 13 \mathrm{~A} \cdots \mathrm{O} 205 ; d(\mathrm{H} \cdots \mathrm{A})=1.75$ and $1.65 \AA, d(\mathrm{D} \cdots \mathrm{A})=2.73(1)$ and 2.63(2) $\AA$ and $\angle(\mathrm{D}-\mathrm{H} \cdots \mathrm{A})=169.7$ and $172.0^{\circ}$, respectively). In addition, very weak $\pi \cdots \pi$ interactions are observed between the layers. Removal of the solvent (by exposing the crystals to air for a couple of minutes) results in destruction of the structure (confirmed by single-crystal and powder X-ray diffraction; see ESI†).

The IR spectrum of 1 shows the bands for the coordinated carboxylate group at 1670 and $1594 \mathrm{~cm}^{-1}$, the coordinated water molecule at $3442 \mathrm{~cm}^{-1}$ and the $\mathrm{P}=\mathrm{O}$ group at $1181 \mathrm{~cm}^{-1}$. Thermogravimetric analysis (TGA) of 1 after drying overnight in air indicated loss of one water molecule and three $\mathrm{dmf}$ molecules (calcd and observed 7.09\%) in the range of 100 to $200{ }^{\circ} \mathrm{C}$. No mass loss was detected between 200 and $400{ }^{\circ} \mathrm{C}$, confirming the thermal stability of 1 up to $400{ }^{\circ} \mathrm{C}$. Gradual decomposition occurred above $400{ }^{\circ} \mathrm{C}$; the free ligand $\mathbf{H}_{2} \mathbf{L}$ is thermally stable up to $420^{\circ} \mathrm{C}^{22}$ (see ESI $\dagger$ ).

\section{Luminescence properties}

The free organic linker $\mathbf{H}_{2} \mathbf{L}$ and compound $\mathbf{1}$ show violet-blue emission on excitation with a UV lamp (Fig. 4a and 5a) at room temperature as solids. All emission bands are slightly unsymmetrical Gaussian-shaped. For $\mathbf{H}_{\mathbf{2}} \mathbf{L}$, the emission spectrum is centred invariably at $25574 \mathrm{~cm}^{-1}$ for different excitation energies, e.g., $30864 \mathrm{~cm}^{-1}$, with full width at half maximum (FWHM) of $3812 \mathrm{~cm}^{-1}$ (Fig. 4b). A comparable behaviour is observed for the emission spectrum of 1 (Fig. 5b), which is centred at $24767 \mathrm{~cm}^{-1}$, about $807 \mathrm{~cm}^{-1}$ red-shifted in comparison to $\mathbf{H}_{2} \mathbf{L}$ and the width reduced ( $\mathrm{FWHM}=$ $3370 \mathrm{~cm}^{-1}$ ). The similar positions of the emission bands in $\mathbf{H}_{2} \mathbf{L}$ and $\mathbf{1}$ result in similar colour coordinates $\left(\mathbf{H}_{2} \mathbf{L}: x=\right.$ $0.1697, y=0.0801$ and 1: $x=0.1595, y=0.0396$, Fig. 6 ).

As discussed previously, ${ }^{20 f}$ the positions of the bands can be explained by the different dihedral angles of the aromatic rings in $\mathbf{1}$ and $\mathbf{H}_{2} \mathbf{L}$. In general, a smaller dihedral angle results in enhanced interactions of the $\pi$ electrons, shifting the emission bands to lower energies. Here, the smaller dihedral angles between the binaphthyl rings in $1\left(76.7(3)^{\circ}\right.$ and $\left.79.6(4)^{\circ}\right)$ compared to that of $82.05(4)^{\circ}$ in the corresponding $4,4^{\prime}$ substituted binaphthyl, ${ }^{22}$ explain the red shift of 1 (Fig. 5b). Although the dihedral angles in the excited states are unknown, it can be assumed that the conformations will not change remarkably during the excitation processes in the rigid structures. The differences in widths of the emission bands 

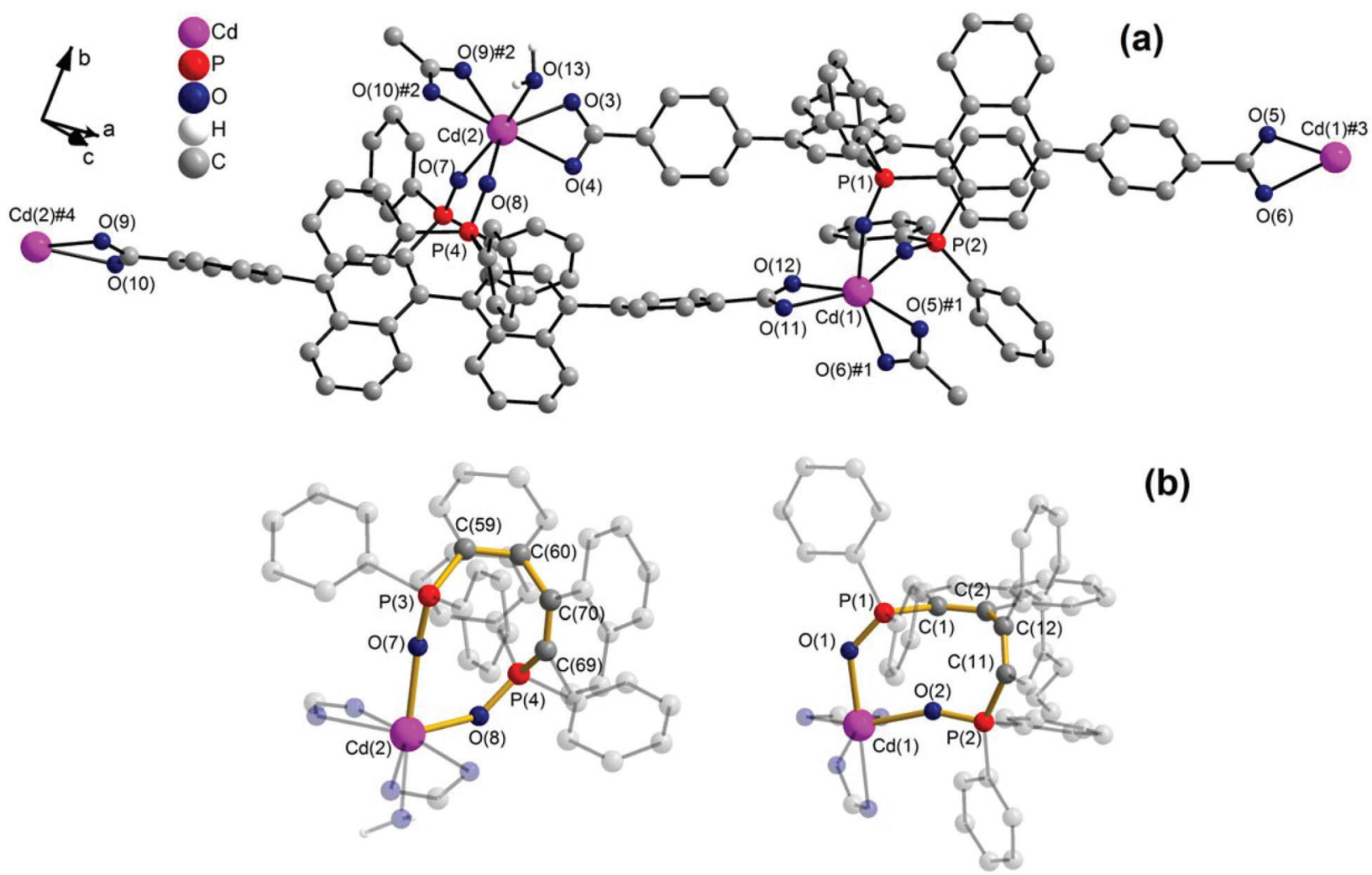

(b)

Fig. 1 (a) Section of the two-dimensional network of 1 , showing hexa- (Cd1) and heptacoordinated (Cd2) metal centres, with an $\mu_{3}, \eta^{2}: \eta^{2}: \eta^{2}$ coordination mode of the dianionic ligand. Symmetry transformations used to generate equivalent atoms: \#1: $-x+3 / 2, y-1 / 2,-z+2 ; \# 2:-x+1 / 2, y+$ 1/2, $-z+1 ; \# 3:-x+3 / 2, y+1 / 2,-z+2 ; \# 4:-x+1 / 2, y-1 / 2,-z+1$; (b) Nine-member rings formed from Cd1 and Cd2 with phosphine-oxide moiety.

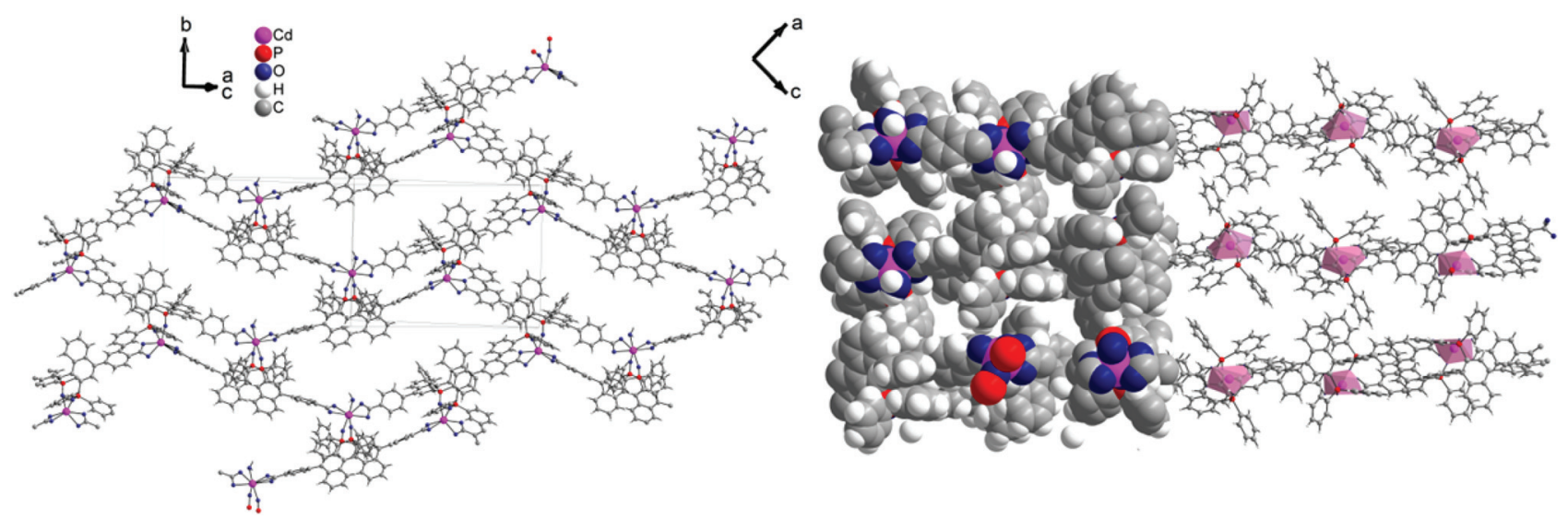

Fig. 2 [1̄01] layers of 1 (left) and space-filling model and polyhedral design (right), Diamond. ${ }^{25}$

can most probably be explained by distinct interatomic distances of the excited states relative to the ground states of these two compounds. Obviously, the interatomic distance of the excited state is smaller for $\mathbf{1}$ than for $\mathbf{H}_{2} \mathbf{L}$, perhaps due to the more rigid structure of $\mathbf{1}$.

Similarly, in both cases, the excitation spectra consist of a broad band which extends over the UV range. The onsets of the excitation bands are at $26625 \mathrm{~cm}^{-1}\left(\mathbf{H}_{2} \mathbf{L}\right)$ and $25325 \mathrm{~cm}^{-1}$
(1) and they show intensity maxima at $29464 \mathrm{~cm}^{-1}\left(\mathbf{H}_{2} \mathbf{L}\right)$ and $27475 \mathrm{~cm}^{-1}$ (1), followed by an intensity decrease at higher excitation energies $\left(>36000 \mathrm{~cm}^{-1}\right)$. Therefore, the similarity in position and shape of the excitation and emission spectra of $\mathbf{H}_{2} \mathbf{L}$ and 1 provide reliable evidence for assigning the optical properties of $\mathbf{1}$ to ligand-based excitation and emission. A further indication for this assignment is the similarity between the excitation spectrum of $1\left(\tilde{\nu}_{\mathrm{em}}=24752 \mathrm{~cm}^{-1}\right.$, 
Table 1 Selected bond lengths and bond angles of 1

\begin{tabular}{lllr}
\hline Bond lengths $[\AA]$ & & Bond angles [0] & \\
\hline $\mathrm{Cd}(1)-\mathrm{O}(1)$ & $2.209(5)$ & $\mathrm{O}(1)-\mathrm{Cd}(1)-\mathrm{O}(2)$ & $79.8(2)$ \\
$\mathrm{Cd}(1)-\mathrm{O}(2)$ & $2.234(5)$ & $\mathrm{O}(1)-\mathrm{Cd}(1)-\mathrm{O}(5) \# 1$ & $98.0(2)$ \\
$\mathrm{Cd}(1)-\mathrm{O}(5) \# 1$ & $2.283(5)$ & $\mathrm{O}(2)-\mathrm{Cd}(1)-\mathrm{O}(5) \# 1$ & $91.5(2)$ \\
$\mathrm{Cd}(1)-\mathrm{O}(6) \# 1$ & $2.336(5)$ & $\mathrm{O}(5) \# 1-\mathrm{Cd}(1)-\mathrm{O}(6) \# 1$ & $57.1(2)$ \\
$\mathrm{Cd}(1)-\mathrm{O}(11)$ & $2.297(6)$ & $\mathrm{O}(1)-\mathrm{Cd}(1)-\mathrm{O}(11)$ & $94.7(2)$ \\
$\mathrm{Cd}(1)-\mathrm{O}(12)$ & $2.292(5)$ & $\mathrm{O}(12)-\mathrm{Cd}(1)-\mathrm{O}(11)$ & $55.9(2)$ \\
$\mathrm{Cd}(2)-\mathrm{O}(3)$ & $2.437(7)$ & $\mathrm{O}(4)-\mathrm{Cd}(2)-\mathrm{O}(3)$ & $53.2(2)$ \\
$\mathrm{Cd}(2)-\mathrm{O}(4)$ & $2.291(5)$ & $\mathrm{O}(9) \# 2-\mathrm{Cd}(2)-\mathrm{O}(10) \# 2$ & $53.9(2)$ \\
$\mathrm{Cd}(2)-\mathrm{O}(7)$ & $2.301(6)$ & $\mathrm{O}(10) \# 2-\mathrm{Cd}(2)-\mathrm{O}(13)$ & $81.4(2)$ \\
$\mathrm{Cd}(2)-\mathrm{O}(8)$ & $2.253(5)$ & $\mathrm{O}(8)-\mathrm{Cd}(2)-\mathrm{O}(7)$ & $81.5(2)$ \\
$\mathrm{Cd}(2)-\mathrm{O}(9) \# 2$ & $2.349(6)$ & $\mathrm{P}(1)-\mathrm{O}(1)-\mathrm{Cd}(1)$ & $133.3(3)$ \\
$\mathrm{Cd}(2)-\mathrm{O}(10) \# 2$ & $2.409(6)$ & $\mathrm{P}(2)-\mathrm{O}(2)-\mathrm{Cd}(1)$ & $157.4(3)$ \\
$\mathrm{Cd}(2)-\mathrm{O}(13)$ & $2.409(8)$ & $\mathrm{P}(3)-\mathrm{O}(7)-\mathrm{Cd}(2)$ & $163.8(3)$ \\
$\mathrm{P}(1)-\mathrm{O}(1)$ & $1.520(6)$ & $\mathrm{P}(4)-\mathrm{O}(8)-\mathrm{Cd}(2)$ & $138.9(4)$ \\
$\mathrm{P}(2)-\mathrm{O}(2)$ & $1.497(5)$ & & \\
$\mathrm{P}(3)-\mathrm{O}(7)$ & $1.495(6)$ & & \\
$\mathrm{P}(4)-\mathrm{O}(8)$ & $1.476(6)$ & &
\end{tabular}

Symmetry transformations used to generate equivalent atoms: $\# 1:-x+$ $3 / 2, y-1 / 2,-z+2 ; \# 2:-x+1 / 2, y+1 / 2,-z+1$.

Fig. 5d) and the reflection spectrum of $\mathbf{H}_{2} \mathbf{L}$ (Fig. 4d). Thus, a decrease of the reflection intensity of $\mathbf{H}_{2} \mathbf{L}$ is observed for energies larger than $20000 \mathrm{~cm}^{-1}$, more pronounced for energies higher than $26000 \mathrm{~cm}^{-1}$. Moreover, there is a maximum in the absorption intensity at $29000 \mathrm{~cm}^{-1}$, strongly overlapping in position and shape with the excitation spectrum of $\mathbf{1}$. In this context, ligand-based luminescence is generally expected for coordination compounds in which the metal ion does not show $\mathrm{d}-\mathrm{d}$ or $\mathrm{f}-\mathrm{f}$ electronic transitions, e.g., metal ions with a $\mathrm{d}^{10}$ configuration, such as $\mathrm{Cd}^{2+}, \mathrm{Zn}^{2+}$ and $\mathrm{Ag}^{+}$, and little or no electronic interaction between the metal ion and the organic ligand is observed. ${ }^{5}$

The strong excitation bands are therefore caused by $S_{0} \rightarrow S_{1}$ transition of the aromatic units in $\mathbf{L}$ or $\mathbf{H}_{2} \mathbf{L}$. Also, the emission bands can be assigned to $\mathrm{S}_{1}$ rather than $\mathrm{T}_{1}$ emission due to the relatively small differences between the emission and excitation maxima (3980 $\mathrm{cm}^{-1}$ for $\mathbf{H}_{2} \mathbf{L}$ and $2708 \mathrm{~cm}^{-1}$ for $\left.\mathbf{1}\right)$. If this assumption is true, the larger Stokes shift of $\mathbf{H}_{2} \mathbf{L}$ compared to $\mathbf{1}$ also indicates a larger increase in the interatomic distance of the excited state relative to the ground state in $\mathbf{H}_{2} \mathbf{L}$ and would agree with the observation of different widths of the emission bands.

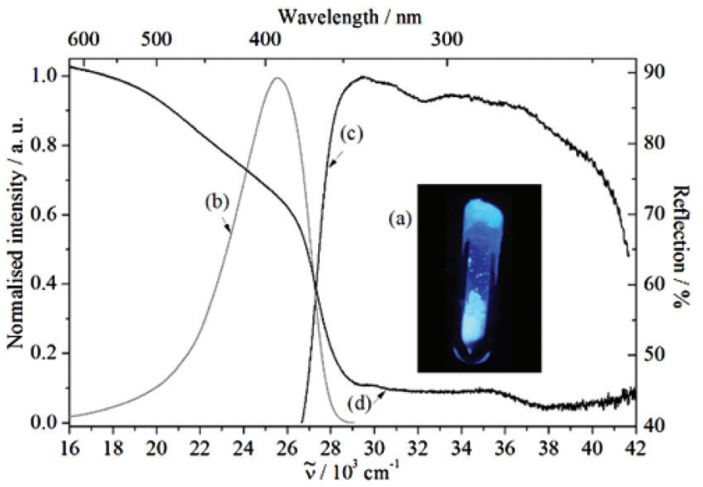

Fig. 4 (a) Violet-blue luminescence of (S)-4,4'-bis(4-carboxyphenyl)2,2'-bis(diphenylphosphinoyl)-1,1'-binaphthyl $\left(\mathrm{H}_{2} \mathrm{~L}\right)$, when illuminated with UV light. (b) Emission $\left(\tilde{\nu}_{\mathrm{ex}}=30864 \mathrm{~cm}^{-1}\right)$, (c) excitation $\left(\tilde{\nu}_{\mathrm{em}}=\right.$ $25445 \mathrm{~cm}^{-1}$ ), and (d) reflection spectra of $\mathrm{H}_{2} \mathrm{~L}$.

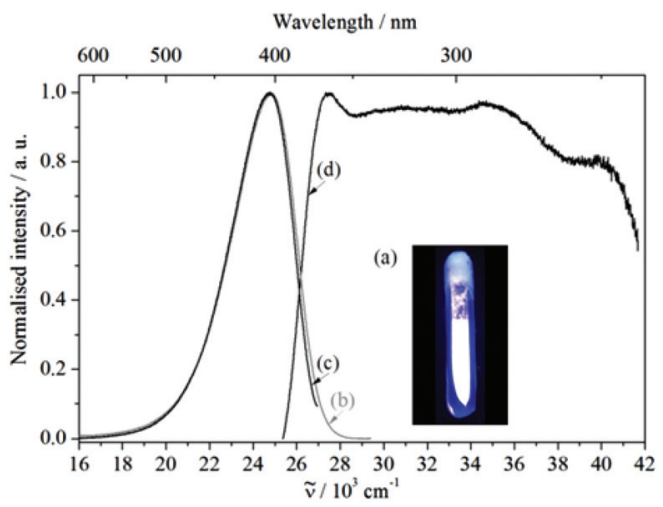

Fig. 5 (a) Violet-blue luminescence of 1 , when illuminated with UV light. Emission (b) $\tilde{\nu}_{\mathrm{ex}}=27397 \mathrm{~cm}^{-1}$ and (c) $\tilde{\nu}_{\mathrm{ex}}=30769 \mathrm{~cm}^{-1}$ as well as (d) excitation $\left(\tilde{\nu}_{\mathrm{em}}=24752 \mathrm{~cm}^{-1}\right)$ spectra of compound 1 .

The quantum yields (QY) of solid $\mathbf{H}_{2} \mathbf{L}(33 \%)$ and $\mathbf{1}(42 \%)$ are considerably high, and indicate decreased loss of efficiency of the ligand-based luminescence in $\mathbf{1}$. This enhancement is related to an increase in structural rigidity in the coordination polymer $1 .^{5}$ In general, there is relatively low vibrational quenching in the case of both compounds, which is quite uncommon for such kind of compounds with large vibrational energies.
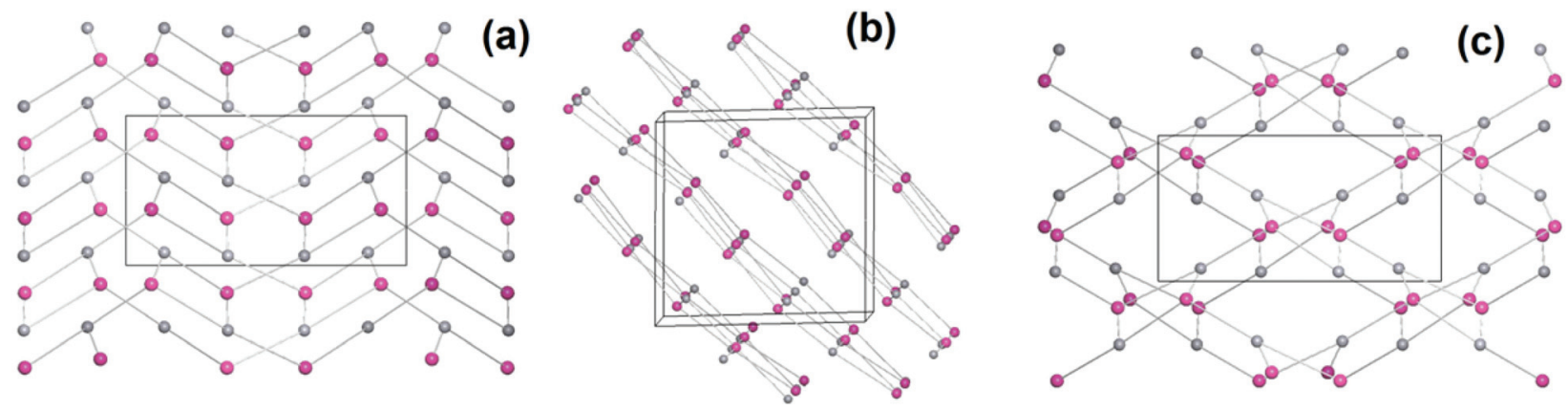

Fig. 3 Simplified two-dimensional network of 1, 3-c net, with Schläfli symbol $\left\{4.8^{2}\right\}$, with views along the (a) [100], (b) [010] and (c) [001] direction; red spheres: $\mathrm{Cd}$, grey spheres and lines: ligand representations. 


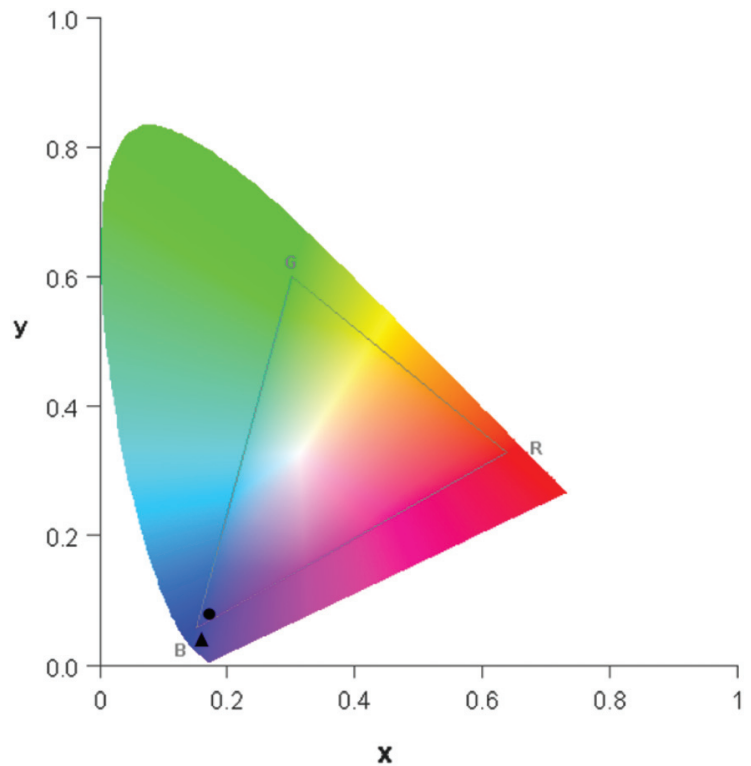

Fig. 6 Plot of colour coordinates in the CIE 1931 chromaticity diagram for $\mathrm{H}_{2} \mathrm{~L}(\bullet)$ and $1(\mathbf{\Delta})$.

Luminescence measurements at low temperatures, e.g., at $10 \mathrm{~K}$, are important for studying possible additional electronic transitions, which may be quenched at room temperature. Furthermore, 1 was heated close to the decomposition temperature $(650 \mathrm{~K}$, see ESI $\dagger$ ) to investigate the effect of increasing temperature on the emission intensity and the maximum shift. As shown in Fig. 7, the emission spectrum of 1 is very similar in shape and position at temperatures between 10 and $650 \mathrm{~K}$ and no additional electronic transitions were detected. The maximum of the emission band located at $25439 \mathrm{~cm}^{-1}$ at $10 \mathrm{~K}$ is red-shifted to $25192 \mathrm{~cm}^{-1}$ at $650 \mathrm{~K}$. Such red shifts are generally observed and can be explained by different effects: by occupation of higher vibronic levels and partly by distortion of the harmonic potentials of the excited electronic state at high temperatures.

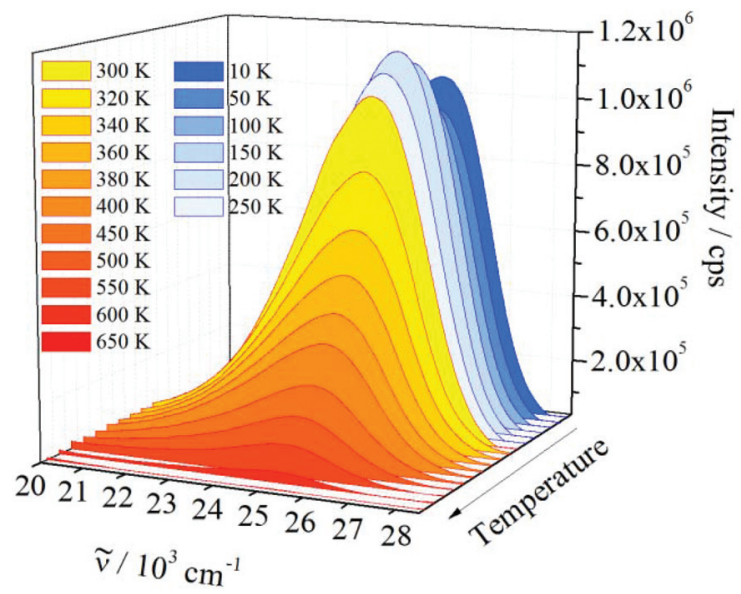

Fig. 7 Effect of temperature increase on the emission spectrum $\left(\tilde{\nu}_{\mathrm{ex}}=\right.$ $30769 \mathrm{~cm}^{-1}$ ) of 1 .

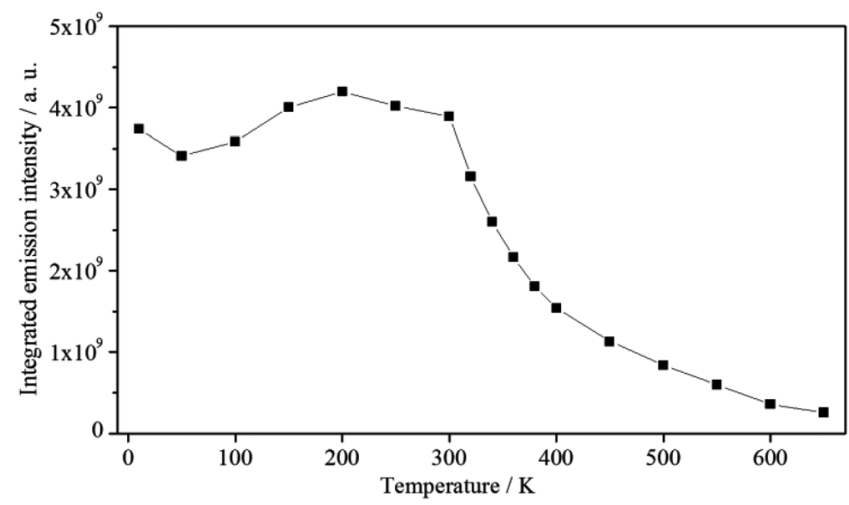

Fig. 8 Exponential decay of the integrated emission intensity ( $\tilde{\nu}_{\text {ex }}=$ $30303 \mathrm{~cm}^{-1}$ ) of 1 with increasing temperature.

Between $10 \mathrm{~K}$ and room temperature $(300 \mathrm{~K})$, the emission intensity of 1 shows an unusual behaviour. In order to roughly quantify the variation of the emission intensity, the curves of the emission spectra presented in Fig. 7 were integrated and plotted against the temperature (Fig. 8).

Initially, the intensity decreases by $c a$. $10 \%$ from 10 to $50 \mathrm{~K}$, gradually increases by about $20 \%$, reaching the maximum value at $200 \mathrm{~K}$, and is approximately constant up to $300 \mathrm{~K}$. The initial decrease in emission intensity is expected due to the enhanced loss of excitation energy by non-radiative transitions. However, the increase in emission intensity between 50 and $200 \mathrm{~K}$ is rather unusual. Probably, the excited states of the ligands and the states of quenching moieties are arranged relative to each other in such a way that quenching is reduced in this temperature range compared to low temperatures, while quenching processes become dominant at higher temperatures. However, further experiments are necessary to investigate and prove this assumption. Between 300 and $650 \mathrm{~K}$ an exponential decrease of the emission intensity is observed. Such a large energy loss caused by non-radiative transitions is commonly observed for luminescent materials at high temperatures.

\section{Experimental section}

\section{Materials and general methods}

Commercial reagents were used as purchased without further purification. (S)-4,4'-bis(4-carboxyphenyl)-2,2'-bis(diphenylphosphinoyl)-1,1'-binaphthyl $\left(\mathbf{H}_{2} \mathbf{L}\right)$ was prepared according to the literature procedure. ${ }^{22}$ The IR spectra were recorded on a Perkin-Elmer Spectrum 2000 FTIR spectrometer by using $\mathrm{KBr}$ pellets in the range of $4000-500 \mathrm{~cm}^{-1}$. Elemental analysis was performed with a Heraeus Vario EL CHN-O analyzer. Thermal analyses were carried out on a Netzsch STA/QMS system 409/ 429-403 thermal analyzer from room temperature to $900{ }^{\circ} \mathrm{C}$ with a heating rate of $10^{\circ} \mathrm{C} \mathrm{min}^{-1}$ under helium atmosphere.

\section{Synthesis of $\left[\left\{\mathrm{Cd}_{2}(\mathrm{~L})_{2}\left(\mathrm{H}_{2} \mathrm{O}\right)\right\} \cdot 18 \mathrm{dmf}\right]_{n}(1)$}

Solvothermal synthesis of $\mathbf{1}$ was accomplished in a stainless steel autoclave under autogenic pressure with an appropriate 
Teflon vessel (Parr), $15 \mathrm{~mL}$ volume. The temperature program in a ULE400 oven (Memmert) was regulated by using the software Celsius 2005 (Version 6.1). A mixture of $\mathrm{Cd}\left(\mathrm{NO}_{3}\right)_{2} \cdot 4 \mathrm{H}_{2} \mathrm{O}$ $(0.024 \mathrm{~g}, 0.078 \mathrm{mmol}),(S)-\mathbf{H}_{2} \mathbf{L}(0.02 \mathrm{~g}, 0.022 \mathrm{mmol})$ and $\mathrm{dmf}$ $\left(10 \mathrm{~mL}\right.$ ) was progressively heated to 65,75 and $85{ }^{\circ} \mathrm{C}$ (each for $24 \mathrm{~h}$ ), and cooled to room temperature over $3 \mathrm{~d}$. Colourless crystals of 1 were obtained, collected by filtration, washed with $\operatorname{dmf}(3 \times 5 \mathrm{~mL})$ and dried at room temperature. Yield: $23 \mathrm{mg}$ (62.5\% based on $\mathbf{H}_{2} \mathrm{~L}$ ). Anal. Calcd for 1-3 dmf (\%): C, 61.88; $\mathrm{H}, 5.90$; N, 6.72; Found: C, 60.00, H, 5.90, N, 6.50. IR ( $\mathrm{KBr}$ pellet, $\mathrm{cm}^{-1}$ ): 3442 (br, OH), 3055 (w, C-H aryl), 2928 (w, C-H), 2342 (w), 1670 (s, $\left.\nu_{\text {as }} \mathrm{COO}\right), 1594$ (m, $\left.\nu_{\mathrm{s}} \mathrm{COO}\right), 1540(\mathrm{~m}), 1498$ (w), 1438 (m, P- $\mathrm{C}_{6} \mathrm{H}_{5}$ ), 1389 (s), 1256 (s), 1181 (s, P=O), 1098 (s), 1019 (m), 974 (w), 865 (s), 792 (s), 756 (w, C-H), 722 (s), 698 (s, P-C), 663 (s), 594 (s), 545 (s, C-H), 471 (w).

\section{Crystal structure determination}

Data collection for colourless crystals of $\mathbf{1}$ was performed on a Gemini-S CCD diffractometer (Agilent Technologies) with $\mathrm{Cu}-\mathrm{K}_{\alpha}$-radiation $(\lambda=1.54184 \AA)$ at $130(2) \mathrm{K}$ and omega scan rotation. Data collection and data reduction were done with CrysAlisPro including the program SCALE3 ABSPACK for empirical absorption correction. ${ }^{26}$ Anisotropic refinement of all non-hydrogen atoms, except dmf molecules, with SHELXL-97. ${ }^{27}$ All hydrogen atoms were calculated on idealised positions by using the riding model. It was possible to locate the water and eight non-disordered of the $18 \mathrm{dmf}$ molecules of the asymmetric unit. With the exception of water, these eight solvent molecules were refined isotropically. 181 restraints were used to model the highly disordered dmf molecules. All other solvent molecules were found to be extremely disordered and poorly defined. The $h k l$ file was corrected for these disordered solvent molecules by using the program SQUEEZE. ${ }^{28}$ The total SQUEEZE electron count revealed 1586 electrons for a volume of $5924 \AA^{3}$ (voids smaller than $50 \AA^{3}$ were not taken into account). Due to this electron count, $40 \mathrm{dmf}$ molecules of the unit cell, i.e. $10 \mathrm{dmf}$ molecules of the asymmetric unit were removed. The resulting volume of approximately $148 \AA^{3}$ for one of these disordered dmf molecules correlates well with the reported volume for non-disordered $\mathrm{dmf}$ molecules $\left(102 \AA^{3}\right),{ }^{29}$ Structure figures were generated with Diamond-3. ${ }^{25}$ Crystallographic data for $\left[\left\{\mathrm{Cd}_{2}(\mathrm{~L})_{2}\left(\mathrm{H}_{2} \mathrm{O}\right)\right\} \cdot 18 \mathrm{dmf}\right]_{n} \quad$ (1): $\mathrm{C}_{170} \mathrm{H}_{204} \mathrm{Cd}_{2} \mathrm{~N}_{18} \mathrm{O}_{31} \mathrm{P}_{4}, M=3344.19 \mathrm{~g} \mathrm{~mol}^{-1}$, space group $C 2$, $a=32.8047(8), b=16.8286(5), c=31.6834(8) \AA, \alpha=90, \beta=$ 91.867(2), $\gamma=90^{\circ}, V=17481.8(8) \AA^{3}, Z=4, \rho_{\text {calcd }}=1.271 \mathrm{Mg} \mathrm{m}^{-3}$, $\mu\left(\mathrm{Cu}_{\mathrm{K \alpha}}\right)=2.894 \mathrm{~mm}^{-1}$. Least-squares refinements based on 48559 reflections (18286 independent reflections and 1360 parameters) led to convergence. For $I>2 \sigma(I)$ the final $R_{1}=$ $0.0604, \mathrm{w} R_{2}=0.1578$, Flack parameter $=0.009(6)$ and GOF $=$ 1.000 .

\section{Luminescence measurements}

Photoluminescence investigations at room and low temperature $(c a .10 \mathrm{~K})$ on solid samples sealed in silica ampoules were carried out with a Jobin Yvon fluorescence spectrometer (Fluorolog 3) equipped with two $0.22 \mathrm{~m}$ double monochromators (SPEX, 1680) and a $450 \mathrm{~W}$ xenon lamp. Cooling to $10 \mathrm{~K}$ was achieved by a closed-cycle He cryostat (Janis Research). Measurements at high temperature (up to $650 \mathrm{~K}$ ) were carried out with a Jobin Yvon fluorescence spectrometer (FluoroMax), equipped with two monochromators and a $150 \mathrm{~W}$ xenon lamp, combined with an attached oven. The emission spectra were corrected for photomultiplier sensitivity, the excitation spectra for lamp intensity and both for the transmission of the monochromators. Quantum yields of solid samples were measured with a Fluorolog 3 fluorescence spectrometer having an additional Ulbricht sphere. For reflection measurements in the UV/Vis range, a Cary 5000 instrument (Varian) was used.

\section{Conclusions}

Chiral coordination polymer $\mathbf{1}$ based on cadmium(II) and (S)-4,4'-bis(4-carboxyphenyl)-2,2'-bis(diphenylphosphinoyl)-1,1'binaphthyl $\left(\mathbf{H}_{2} \mathbf{L}\right)$ as linker was synthesised solvothermally and fully characterised. Compounds $\mathbf{H}_{2} \mathbf{L}$ and $\mathbf{1}$ show intense blue emission when excited with UV light. Emission spectra consist of nearly Gaussian shaped bands at $25574 \mathrm{~cm}^{-1}$ for $\mathbf{H}_{2} \mathbf{L}$ and $24767 \mathrm{~cm}^{-1}$ for 1. Similarities between the excitation and emission spectra of $\mathbf{1}$ and $\mathbf{H}_{2} \mathbf{L}$ are indicative of $\mathrm{S}_{1} \rightarrow \mathrm{S}_{0}$ transitions of $\mathbf{L}$. Moreover, the quantum efficiency increases from $33 \%$ in $\mathbf{H}_{2} \mathbf{L}$ to the remarkably high value of $42 \%$ in $\mathbf{1}$, which indicates that incorporation of $\mathbf{L}$ into the rigid framework prevents the loss of excitation energy by non-radiative transitions. The emission intensity of 1 increases between $10 \mathrm{~K}$ and room temperature, and decreases exponentially up to $650 \mathrm{~K}$.

\section{Acknowledgements}

This work was supported by the Faculty for the Future (FFTF-Schlumberger Foundation for Women in Science and Engineering, doctoral fellowship for W.W.L.). Support from the EU COST Action CM0802 PhoSciNet is gratefully acknowledged. We thank Chemetall GmbH and BASF SE for generous donations of chemicals. We thank MSc Marcel Handke and MSc Carola Stenz for PXRD measurement and TOPOS analysis.

\section{References}

1 (a) O. M. Yaghi and H. Li, J. Am. Chem. Soc., 1995, 117, 10401-10402; (b) O. M. Yaghi, D. A. Richardson, G. Li, E. Davis and T. L. Groy, Mater. Res. Soc. Symp. Proc., 1995, 371, 15-19; (c) H. Li, M. Eddaoudi, M. O'Keeffe and O. M. Yaghi, Nature, 1999, 402, 276-279.

2 (a) M. J. Zaworotko, Nat. Chem., 2009, 1, 267-268; (b) J. J. Perry IV, J. A. Perman and M. J. Zaworotko, Chem. Soc. Rev., 2009, 38, 1400-1417 and references therein. 
3 S. R. Batten, D. R. Turner and M. S. Neville, in Coordination Polymers: Design, Analysis and Application, RSC, Cambridge, 2009.

4 (a) S.-I. Noro, S. Kitagawa, M. Kondo and K. Seki, Angew. Chem., 2000, 112, 2161-2164, (Angew. Chem., Int. Ed., 2000, 39, 2082-2084); (b) S. Shimomura, S. Horike and S. Kitagawa, Stud. Surf. Sci. Catal., 2007, 170B, 19831990.

5 D. Farrusseng, in Metal-Organic Frameworks-Applications from Catalysis to Gas Storage, Wiley-VCH, Weinheim, 1st edn, 2011.

6 (a) M. D. Allendorf, C. A. Bauer, R. K. Bhakta and R. J. T. Houk, Chem. Soc. Rev., 2009, 38, 1330-1352; (b) Y. Cui, Y. Yue, G. Qian and B. Chen, Chem. Rev., 2012, 112, 1126-1162.

7 (a) C. A. Bauer, T. V. Timofeeva, T. B. Settersten, B. D. Patterson, V. H. Liu, B. A. Simmons and M. D. Allendorf, J. Am. Chem. Soc., 2007, 129, 7136-7144; (b) X.-L. Wang, Y.-F. Bi, H.-Y. Lin and G.-C. Liu, Cryst. Growth Des., 2007, 7, 1086-1091; (c) Y.-Q. Huang, B. Ding, H.-B. Song, B. Zhao, P. Ren, P. Cheng, H.-G. Wang, D.-Z. Liao and S.-P. Yan, Chem. Commun., 2006, 4906-4908; (d) X. Li, X.-W. Wang and Y.-H. Zhang, Inorg. Chem. Commun., 2008, 11, 832-834.

8 (a) C. J. Holler, P. R. Matthes, M. Adlung, C. Wickleder and K. Müller-Buschbaum, Eur. J. Inorg. Chem., 2012, 33, 54795484; (b) P. J. Calderonea, A. M. Plonka, D. Banerjee, Q. A. Nizami and J. B. Parise, Solid State Sci., 2013, 15, 36-41; (c) X.-H. Zhou, L. Li, H.-H. Li, A. Li, T. Yanga and W. Huang, Dalton Trans., 2013, 42, 12403-12409; (d) J. Rocha, L. D. Carlos, F. A. A. Paz and D. Ananias, Chem. Soc. Rev., 2011, 40, 926-940; (e) H.-M. Wang, Y.-Y. Yang, C.-H. Zeng, T.-S. Chu, Y.-M. Zhu and S. W. Ng, Photochem. Photobiol. Sci., 2013, 12, 1700-1706.

9 (a) H. C. Streit, M. Adlung, O. Shekhah, X. Stammer, H. K. Arslan, O. Zybaylo, T. Ladnorg, H. Gliemann, M. Franzreb, C. Woell and C. Wickleder, ChemPhysChem, 2012, 13, 2699-2702; (b) W.-G. Lu, L. Jiang, X.-L. Feng and T.-B. Lu, Inorg. Chem., 2009, 48, 6997-6999.

10 (a) C.-J. Chen, X.-P. Ye, J.-Y. Gao, W.-P. Xie, X.-R. Ran, S.-T. Yue and Y.-P. Cai, Inorg. Chem. Commun., 2013, 29, 4-10; (b) H. Wang, W. Shi, B. Zhai, J. Ma, J. Xia and P. Cheng, J. Mol. Struct., 2007, 833, 102-107; (c) Q.-R. Fang, G.-S. Zhu, Z. Jin, Y.-Y. Ji, J.-W. Ye, M. Xue, H. Yang, Y. Wang and S.-L. Qiu, Angew. Chem., 2007, 119, 6758-6762, (Angew. Chem., Int. Ed., 2007, 46, 6638-6642); (d) L. Wen, Z. Lu, J. Lin, Z. Tian, H. Zhu and Q. Meng, Cryst. Growth Des., 2007, 7, 93-99.

11 W.-Y. Huanga, Z.-L. Chen, H.-H. Zou, D.-C. Liu and F.-P. Liang, Polyhedron, 2013, 50, 1-9.

12 (a) Y. Cui, H. L. Ngo and W. Lin, Chem. Commun., 2003, 1388-1389; (b) Y. Cui, S. J. Lee and W. Lin, J. Am. Chem. Soc., 2003, 125, 6014-6015; (c) C.-D. Wu and W. Lin, Chem. Commun., 2005, 3673-3675; (d) C.-D. Wu, L. Ma and W. Lin, Inorg. Chem., 2008, 47, 11446-11448; (e) C.-D. Wu, L. Zhang and W. Lin, Inorg. Chem., 2006, 45, 7278-7285; (f) O. R. Evans, H. L. Ngo and W. Lin, J. Am. Chem. Soc., 2001, 123, 10395-10396.

13 (a) B. Kesanli and W. Lin, Coord. Chem. Rev., 2003, 246, 305-326; (b) Q. Gaoa, F.-L. Jianga, M.-Y. Wua, Y.-G. Huanga, L. Chena, W. Wie and M.-C. Hong, J. Solid State Chem., 2009, 182, 1499-1505; (c) C.-D. Wu, H. L. Ngo and W. Lin, Chem. Commun., 2004, 1588-1589; (d) S. J. Lee and W. Lin, J. Am. Chem. Soc., 2002, 124, 4554-4555.

14 (a) A. Hu, H. L. Ngo and W. Lin, J. Am. Chem. Soc., 2003, 125, 11490-11491; (b) C.-D. Wu, A. Hu, L. Zhang and W. Lin, J. Am. Chem. Soc., 2005, 127, 8940-8941; (c) L. Ma, C.-D. Wu, M. M. Wanderley and W. Lin, Angew. Chem., 2010, 122, 8420-8424, (Angew. Chem., Int. Ed., 2010, 49, 8244-8248); (d) L. Ma, J. M. Falkowski, C. Abney and W. Lin, Nat. Chem., 2010, 20, 838-846; (e) Y. Cui, O. R. Evans, H. L. Ngo, P. S. White and W. Lin, Angew. Chem., 2002, 114, 1207-1210, (Angew. Chem., Int. Ed., 2002, 41, 1159-1162); (f) L. Ma, D. J. Mihalcik and W. Lin, J. Am. Chem. Soc., 2009, 131, 4610-4612.

15 (a) M. M. Wanderley, C. Wang, C.-D. Wu and W. Lin, J. Am. Chem. Soc., 2012, 134, 9050-9053; (b) X. Ouyang, Z. Chen, X. Liu, Y. Yang, M. Deng, L. Weng, Y. Zhou and Y. Jia, Inorg. Chem. Commun., 2008, 11, 948-950.

16 (a) L. Li, Z.-G. Ren, N.-Y. Li, Y. Zhang and J.-P. Lang, Inorg. Chim. Acta, 2009, 362, 3910-3914; (b) N.-Y. Li, Z.-G. Ren, D. Liu, R.-X. Yuan, L.-P. Wei, L. Zhang, H.-X. Lia and J.-P. Lang, Dalton Trans., 2010, 39, 4213-4222.

17 (a) M.-C. Brandys and R. J. Puddephatt, J. Am. Chem. Soc., 2001, 123, 4839-4840; (b) M. Frik, J. Jiménez, I. Gracia, L. R. Falvello, S. Abi-Habib, K. Suriel, T. R. Muth and M. Contel, Chem.-Eur. J., 2012, 18, 3659-3674.

18 Q. Gao, M.-Y. Wu, L. Chen, F.-L. Jiang and M.-C. Hong, Inorg. Chem. Commun., 2009, 12, 1238-1241.

19 (a) J. J. Zhang, L. Wojtas, R. W. Larsen, M. Eddaoudi and M. J. Zaworotko, J. Am. Chem. Soc., 2009, 131, 17040-17041; (b) J.-D. Lin, X.-F. Long, P. Lin and S.-W. Du, Cryst. Growth Des., 2010, 10, 146-157; (c) A. D. Burrows, K. Cassar, T. Düren, R. M. W. Friend, M. F. Mahon, S. P. Rigby and T. L. Savarese, Dalton Trans., 2008, 2465-2474; (d) X. Shi, G. Zhu, X. Wang, G. Li, Q. Fang, G. Wu, G. Tian, M. Xue, X. Zhao, R. Wang and S. Qiu, Cryst. Growth Des., 2005, 5, 207-213; (e) R.-Q. Zou, X.-H. Bu and R.-H. Zhang, Inorg. Chem., 2004, 43, 5382-5386; $(f)$ O. A. Michaelides, D. Tsaousis, S. Skoulika, C. P. Raptopoulou and A. Terzis, Acta Crystallogr., Sect. B: Struct. Sci., 1998, 54, 657-662; (g) I. Grosu, P. Lönnecke, L. Silaghi-Dumitrescu and E. Hey-Hawkins, Z. Anorg. Allg. Chem., 2011, 637, 17221727.

20 (a) F. Guo, F. Wang, H. Yang, X. Zhang and J. Zhang, Inorg. Chem., 2012, 51, 9677-9682; (b) H. Xu, W. Bao, Y. Xu, X. Liu, X. Shen and D. Zhu, CrystEngComm, 2012, 14, 57205722; (c) F. A. A. Paz, Y. Z. Khimyak, A. D. Bond, J. Rocha and J. Klinowski, Eur. J. Inorg. Chem., 2002, 2823-2828; (d) Q.-R. Fang, G.-S. Zhu, Z. Jin, Y.-Y. Ji, J.-W. Ye, M. Xue, H. Yang, Y. Wang and S.-L. Qiu, Angew. Chem., 2007, 119, 6758-6762, (Angew. Chem., Int. Ed., 2007, 46, 6638-6642); 
(e) R. Wang, M. Hong, J. Luo, R. Cao and J. Weng, Chem. Commun., 2003, 1018-1019; (f) W. W. Lestari, P. Lönnecke, M. B. Sárosi, H. C. Streit, M. Adlung, C. Wickleder, M. Handke, W. D. Einicke, R. Gläser and E. Hey-Hawkins, CrystEngComm, 2013, 15, 3874-3884.

21 R.-Q. Zhonga, R.-Q. Zoua, D. S. Pandey, T. Kiyobayashi and Q. Xua, Inorg. Chem. Commun., 2008, 11, 951-953.

22 W. W. Lestari, H. Zaake-Hertling, P. Lönnecke and E. Hey-Hawkins, Z. Anorg. Allg. Chem., 2013, 639, 2589-2596.

23 TOPOS 4.0; V. A. Blatov, IUCr CompComm Newsl., 2006, 7, 4-38.

24 M. O’Keeffe, M. A. Peskov, S. J. Ramsden and O. M. Yaghi, Acc. Chem. Res., 2008, 41, 1782-1789.
25 Diamond, Version 3.2i, Klaus Brandenburg, Crystal Impact GbR, Bonn, Germany.

26 CrysAlisPro, Data Collection and Data Reduction Software Package Including SCALE3 ABSPACK for Empirical Absorption Correction using Spherical Harmonics, version 1.171.35.21, release 20-01-2012 CrysAlis171 .NET, Agilent Technologies.

27 SHELX includes SHELXS97, SHELXL97: G. M. Sheldrick, Acta Cryst., 2008, A64, 112-122.

28 SQUEEZE; P. van der Sluis and A. L. Spek, Acta Crystallogr., Sect. A: Fundam. Crystallogr., 1990, 46, 194-201.

29 H. Borrmann, I. Persson, M. Sandström and C. M. V. Stålhandske, J. Chem. Soc., Perkin Trans. 2, 2000, 393-402. 